\title{
Avaliação de Desempenho do Processo de Manufatura do Café
}

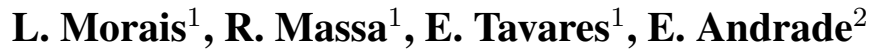 \\ ${ }^{1}$ Centro de Informática \\ Universidade Federal de Pernambuco (UFPE) - Recife - PE - Brazil \\ ${ }^{2}$ Departamento de Informática \\ Universidade Federal Rural de Pernambuco (UFRPE) - Recife - PE - Brazil \\ \{lmfs2,rmfl, eagt\}@cin.ufpe.br, ermeson@deinfo.ufrpe.br
}

\begin{abstract}
Globalization and advanced manufacturing technologies have forced manufacturing firms to increase productivity while reducing costs. At the same time, customers are increasingly demanding better products considering tangible (e.g., smell, color, taste) and intangible (e.g., mark, fair treading, and environmental responsability) attributes. Currently, Brazil consolidates a position as the largest producer and exporter of coffee, accounting for $30 \%$ of the international coffee market. This paper presents a stochastic model for performance evaluation and planning of coffee manufacturing process aiming at reducing the cost and time of the production cycle. An industrial case study shows the practical usability of the proposed models and techniques.
\end{abstract}

\section{Introdução}

Este trabalho apresenta uma abordagem baseada em redes de Petri estocásticas para o planejamento da capacidade de um processo de manufatura de café considerando atributos para a avaliação de desempenho e custo. Mais informações relacionadas as SPNs podem ser encontradas em [German 2000]. As principais contribuições deste trabalho são: (i) a avaliação de desempenho do processo de produção de café a fim de encontrar possíveis gargalos; (ii) apresentar um estudo de caso, mostrando as aplicações deste trabalho; e (iii) a validação dos resultados dos modelos com medidas obtidas a partir de linhas de produção reais de café. Este artigo está organizado da seguinte forma. A Seção 2 detalha o processo de produção do café. Seção 3 detalha o modelo de desempenho desenvolvido para avaliação de desempenho do sistema de manufatura do café. Seção 4 apresenta o estudo de caso no qual foi aplicada a metodologia. A Seção 5 apresenta a avaliação de desempenho do processo de manufatura do café. Finalmente, a Seção 6 conclui este trabalho e apresenta os trabalhos futuros.

\section{Processo de Produção do Café}

O processo de produção de processamento e embalagem do café consiste nos seguintes passos: seleção de grãos, torrefação, moagem e empacotamento do café. Os grãos de café verde são armazenados em silos. Durante o processo de produção dos grãos de café, os mesmos passam por duas etapas (seleção e torrefação) antes de serem moídos e embalados para comercialização. Na primeira etapa, os grãos são limpos. Após a limpeza, os grãos de café selecionados são transferidos para outros silos, e em seguida, enviados para as 
torrefadoras [Embrapa 2005]. Em seguida, ocorrerá a transformação do café torrado em pó homogêneo. Finalmente, o pó de café é empacotado e armazenado nos depósitos e logo o produto está disponível para comercialização.

\section{Modelo de Desempenho}

O modelo SPN obtido foi usado para analisar o fluxo de produção, bem como identificar potenciais gargalos no sistema (ver Figura 1). O modelo de desempenho proposto é composto por seis blocos, onde " $N S G V$ " representa a disponibilidade dos silos de grãos de café verde, " $N S$ " representa a disponibilidade das máquinas selecionadoras de grãos, "NSGS" representa a disponibilidade dos silos de grãos de café selecionados, "NT" representa a disponibilidade das máquinas torradoras de grãos, "NSGTM" representa a disponibilidade dos silos de grãos torrados e moídos, e por fim " $N E$ " representa a disponibilidade das máquinas empacotadoras.

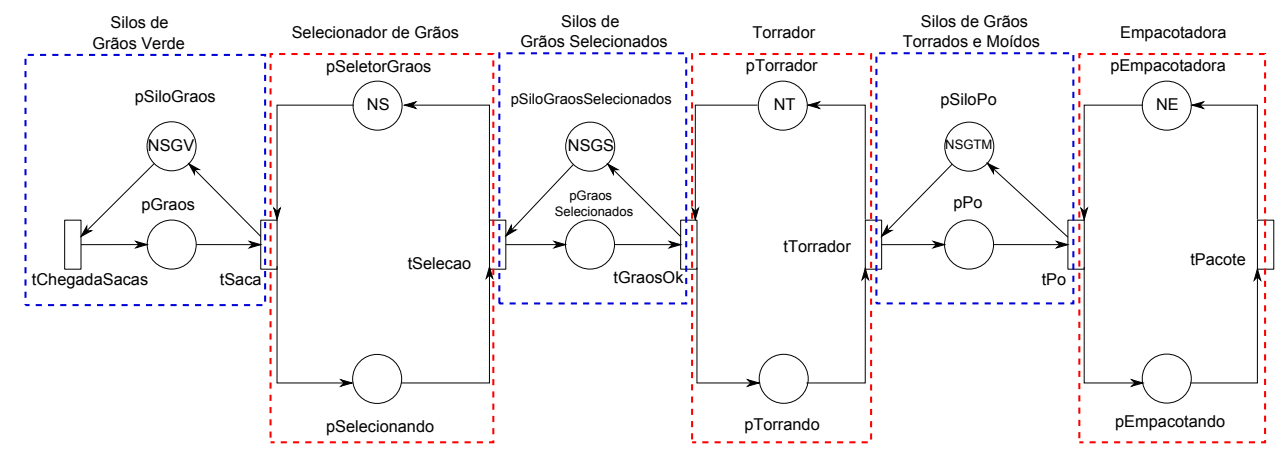

Figura 1. Modelo de Desempenho

O disparo da transição tChegadaSacas representa a chegada de sacas de grãos de café nos silos de grãos verde, e, em seguida, um token é removido do lugar pSiloGraos e um token é depositado no lugar $p$ Graos. Logo após esse processo, os grãos são enviados para as máquinas seletoras de grãos através do disparo da transição $t S a c a$. Em seguida, um token é removido tanto do lugar pSeletorGraos quanto do lugar $p$ Graos, e um token é depositado no lugar $p$ Selecionando. Em seguida, o disparo da transição $t$ Selecao representa o momento em que os grãos que foram selecionados são enviados para outros silos contendo apenas grãos selecionados. Logo após esse processo, os grãos selecionados são enviados para os torrefadores através do disparo da transição tGraosOk. Depois disso, os grãos são torrados (tTorrador) e enviado para silo de pó. Por fim, os grãos torrados e moídos são enviados para as empacotadoras pelo disparo da transição $t P o$, onde o café é empacotado através do disparo da transição tPacote.

\section{Estudo de Caso}

Esta seção apresenta um estudo de caso real realizado em uma indústria brasileira de café. A fábrica localiza-se na região metropolitana do Recife no estado de Pernambuco, onde sua produção é comercializada. A indústria tem capacidade para produzir 500 mil toneladas de café por mês.

\subsection{Validação dos Modelos}

O estudo foi realizado com base nos dados coletados em uma indústria de café, durante o período de dois meses e divididos em oito grupos, onde cada grupo representa os dados 
coletados por semana. Neste trabalho, serão utilizados dados medidos durante uma semana de produção. Para cada atividade do processo de manufatura foi estimado o tempo de execução, isto é, desde o tempo entre chegadas de sacas de café até o tempo entre empacotamento dos grãos torrados e moídos. A medição do tempo de cada atividade foi realizada pelos funcionários da fábrica e fornecidos em planilha para que fossem utilizados no processo de validação dos modelos. Para validar o modelo SPN (ver Figura 1), os dados coletados na indústria do café foram comparados com os dados obtidos pelo modelo. Foi considerada a seguinte quantidade de máquinas no processo de produção: dois silos de grãos de café verde, duas máquinas selecionadoras de grãos, dois silos para grãos selecionados, uma máquina torradora de grãos, dois silos para armazenagem do pó do café e três máquinas empacotadoras. Essa é a configuração real da fábrica utilizada neste estudo. A métrica adotada para a validação do modelo foi a vazão de produção (ver Equação 1):

$$
\text { VazaoProducao }=\sum_{i=1}^{N} P\{\# p \text { Empacotando }=i\} \times i \times W(\text { tPacote })
$$

A Tabela 1 apresenta a comparação entre o resultado da vazão obtida através do modelo e do valor medido da vazão de produção, onde a linha Semana é referente a uma semana de coleta de dados, a coluna Medido representa os dados coletados na indústria estudada e a coluna Modelo representa os dados simulados/calculados pelo modelo SPN.

Tabela 1. Validação dos Resultados $\mathbf{~} \mathbf{k g} / \mathbf{s})$
\begin{tabular}{lcc}
\hline & Medido & Modelo \\
\hline Semana & 230 & 230 \\
\hline
\end{tabular}

\section{Avaliação de Desempenho do Processo de Manufatura do Café}

Esta seção apresenta os resultados da análise de desempenho considerando as diferentes capacidades das máquinas e o melhor custo-benefício para a indústria. A métrica adotada na análise foi a "análise da vazão de produção", ou seja, o throughput da transição tPacote. O throughput determina a média de disparos de uma transição por unidade de tempo. Os gerentes de produção queriam investir na fase de empacotamento do café, pois eles acreditavam que o gargalo do sistema encontrava-se nesta área, devido a frequente ocorrência de problemas com as máquinas empacotadoras, por exemplo, troca da bobina, estouro de pacotes de café, entre outros. Foi realizado o teste $2^{K}$ Fatorial [Montgomery and Runger 2011], onde é possível estudar os efeitos dos diferentes fatores, ou seja, as máquinas, sobre uma variável (produção do café). A partir do teste, diferente do que os gerentes acreditavam, o teste demonstrou que a fase que causava maior impacto sobre o processo de produção era a fase de torrefação. Na Tabela 2 mostramos o percentual de influência de cada máquina durante o processo de produção. Por exemplo, a máquina Selecionadora, tem um percentual de influência de $2,17 \%$ no processo de produção, ou seja, não há gargalo nesta fase da produção. No entanto, não podemos afirmar o mesmo ao falarmos sobre o Torrador. Este tem um percentual de influência de $81,64 \%$, demonstrando ser o gargalo do sistema de produção. 
Tabela 2. Percentual de influência das máquinas no processo de produção

\begin{tabular}{lc}
\hline Máquinas & Participação \\
\hline Selecionador & $2.17 \%$ \\
Torrador & $81.64 \%$ \\
Empacotadora & $4.58 \%$ \\
Selecionador-Torrador & $0.09 \%$ \\
Torrador-Empacotadora & $4.74 \%$ \\
Selecionador-Empacotadora & $3.25 \%$ \\
Selecionador-Torrador-Empacotadora & $3.50 \%$ \\
\hline
\end{tabular}

A partir dessa análise, foram coletados dados de duas máquinas selecionadoras de grãos (SM 30 e SM 40), duas máquinas torrefadoras (TCE 120 e C 480) e duas máquinas empacotadoras (CME 600 e Agility). Foram realizadas oito combinações diferentes de máquinas (selecionadores, torrefadores e empacotadoras) a fim de investir na composição de máquinas que melhor apresentaria vazão de produção e menor custo (ver Figura 2).

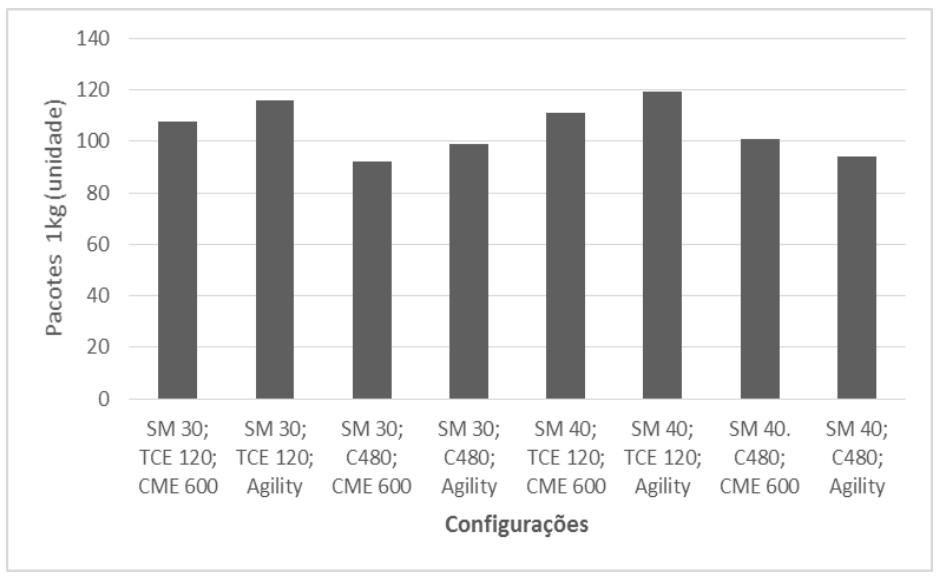

Figura 2. Diferentes combinações de Máquinas - Vazão de Produção.

A transição tSelecao adotada para as máquinas selecionadoras de grãos $S M 30 \mathrm{e}$ $S M 40$, respectivamente, limparem $360 \mathrm{~kg}$ (o correspondente a seis sacas de $60 \mathrm{~kg}$ ) foram respectivamente 540 segundos e 370,2 segundos. A transição tTorrador adotada para as máquinas torradoras $T C E 120$ e $C 480$, respectivamente, torrarem o correspondente a $360 \mathrm{~kg}$ foram respectivamente 720 segundos e 960 segundos. Por fim, a transição tPacote adotada para as máquinas empacotadoras $C M E 600$ e Agility, tiveram respectivamente, a taxa de 90 segundos por pacote e 0,75 segundos por pacote.

Conforme apresentado na Figura 2, podemos observar que a configuração de máquinas que melhor apresenta vazão de produção é o selecionador $S M 40$, o torrador $T C E 120$ e a empacotadora Agility. Como o teste $2^{K}$ Fatorial demonstrou que a máquina com maior influência no desempenho é o Torrador, fixamos o selecionador $S M 40$ e a empacotadora Agility, que obtiveram melhor desempenho nas análises realizadas e vamos aprofundar os estudos avaliando outros tipos de torrador. Foram analisadas seis máquinas torradoras com diferentes taxas de produção (ver Tabela 3). 
Tabela 3. Taxas das seis novas máquinas de torrefação em segundos

\begin{tabular}{c|c|c|c|c|c|c|}
\hline \multirow{2}{*}{ tTorrador } & Opus 20 & Expert 1400 & Smart 2000 & Opus 3G & Expert 2800 & Turbo \\
\cline { 2 - 7 } & 900 & 960 & 840 & 1140 & 1080 & 1200 \\
\hline
\end{tabular}

A Figura 3 apresenta a vazão dessas configurações. Como é possível observar, a configuração SM40 - Smart2000 - Agility teve a melhor vazão. Já a Figura 4 apresenta os valores das configurações. Dessa forma, é possível observar que a configuração SM40 - Smart2000 - Agility, além de apresentar a melhor vazão também apresenta o melhor custo benefício, pois são máquinas de alta potência produtiva e com valores relativamente baixos quando comparadas a máquinas de altos valores e baixa produtividade, por exemplo o torrador Turbo.

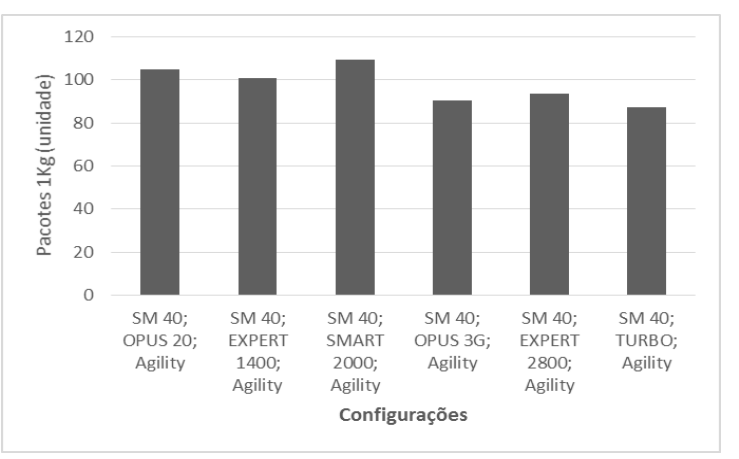

Figura 3. Vazãodas máquinas

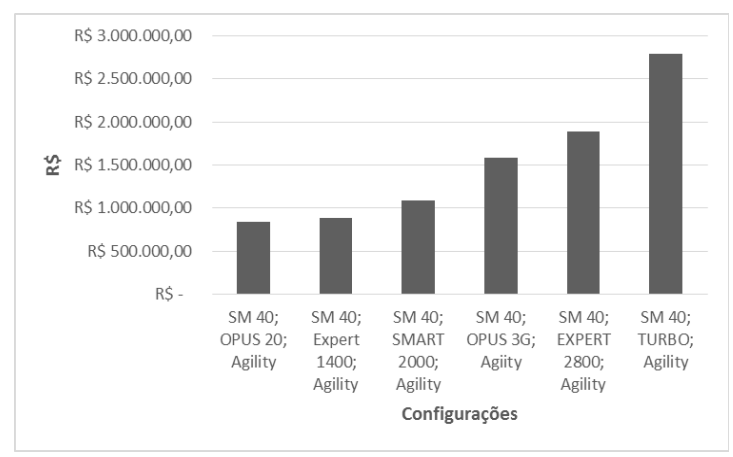

Figura 4. Custo das máquinas

\section{Conclusão}

Este trabalho apresentou uma abordagem baseada em SPN para o planejamento de capacidade do processo de fabricação do café, considerando o desempenho e custo. Um estudo de caso foi realizado em uma indústria de café. Através dos modelos foi possível identificar que o gargalo do processo produtivo estava na fase de torrefação e não na fase de empacotamento como, empiricamente, acreditavam os gerentes de produção. Como trabalhos futuros, propomos a análise do consumo de energia com o objetivo de obter o consumo mínimo de energia para sistemas de produção sem afetar a produção e analisar o impacto da utilização de diferentes fontes de energia na linha de produção.

\section{Referências}

German, R. (2000). Performance Analysis of Communication Systems with NonMarkovian Stochastic Petri Nets. John Wiley \& Sons, Inc. New York, NY, USA, Second Edition edition.

Montgomery, D. C. and Runger, G. C. (2011). Applied Statistics and Probability for Engineers. John Wiley \& Sons, Inc., n. 5 edition.

Embrapa (2005). Cultivo do Café Robusta em Rondônia. Sistema de Produção, 5. Empresa Brasileira de Pesquisa Agropecuária. 